\title{
Elucidating How Environment Affects Patterns of Network Change: A Case Study of the Evolution of an Industrial Network in the Flat Panel Display Sector
}

\author{
Hung-Chun Huang • Hsin-Yu Shih • Tsung-Han Ke • \\ Pai-Yu Liu
}

Received: 22 October 2012 / Accepted: 5 November 2012 /

Published online: 22 November 2012

(C) The Author(s) 2012. This article is published with open access at Springerlink.com

\begin{abstract}
As science and technology policy-makers focus on understanding how industry networks evolve, this study discusses how environmental changes affect the evolution of industrial networks, especially in the flat panel display (FPD) sector. By investigating different environmental scenarios, it can be shown that changes of environmental munificence and environmental uncertainty simultaneously affect industrial network transition and reshape distinctive network formations. Data from 71 countries from 1976 to 2008 have been examined to empirically evaluate their network relationships. This study, thus, demonstrates a longitudinal evolutionary trajectory for the FPD industry and locates the essential transition of technological competition via international technological coevolution. The analytical results demonstrate that different environmental scenarios provide different opportunities for countries to develop their niche competence in the FPD industry. Our findings provide insightful implications for policy-makers and business practitioners involved in dynamic and competitive global industries similar to FPD.
\end{abstract}

Keywords Environmental changes - Industrial network evolution - Flat panel display · Environmental munificence $\cdot$ Environmental uncertainty

\section{Introduction}

Flat panel display (FPD) manufacturing emerged as the first industry to fully develop in a global economy defined more by trade in knowledge than in physical products

H.-C. Huang $(\square) \cdot$ H.-Y. Shih $•$ T.-H. Ke $\cdot$ P.-Y. Liu

Department of International Business Studies, National Chi Nan University, 1, University Rd.,

Puli, Nantou 54561, Taiwan

e-mail: anfang886@gmail.com

H.-C. Huang

Department of Business Administration, Feng Chia University, Taichung, Taiwan 
(Murtha et al. 2001). However, the FPD industry is characterized by large capital investment and accelerated technological development (Mathews 2005). It, therefore, holds a technological advantage in industrialized countries. While stressing the critical role of organizational colocation in FPD development of both technology and industry, previous studies have posited that a new class of global, knowledgedriven manufacturing industries has emerged in which learning, continuity, and speed define competition (Murtha et al. 2001; Spencer 2003). Collaborative networking among countries is, thus, essential for technological advances (Powell et al. 1996; Kogut 2000; Osterloh and Rota 2007). A healthy innovation infrastructure is vital yet independently insufficient to support the environment required to achieve continuous innovation (Furman and Hayes 2004). Countries can increase their technological capacity by obtaining advanced technologies from abroad (Barro and Sala-i-Martin 1997; Grossman and Helpman 1991), and most countries depend on overseas sources of technological progress to increase productivity rather than domestic ones (Keller 2004). More than depending on domestic research and development, a country striving to upgrade its technological capacity must also collaborate with overseas partners (Verspagen and Duysters 2004; Gulati and Gargiulo 1999).

However, a significant amount of innovation has induced technological transition. In addition to a significant amount of innovation, intensive capital and accelerated technological advances facilitate changes in a collaboration network. Previous studies (Castrogiovanni 1991; Dess and Beard 1984; Milliken 1987) have attributed this causality as environmental effects through the simultaneous influence of two widely accepted constructs, i.e., resource munificence and technological uncertainty. The more munificent the environment, the greater the firm's opportunity to acquire available resources (Bruno and Tyebjee 1982). Meanwhile, Burt (1987) indicated that the more the technological uncertainty, the stronger the firm's relationships to reinforce its alliances. Thus, the alteration of technological uncertainty and resource munificence can be regarded as environmental changes (Koka et al. 2006). An environmental change evokes a pattern of network change in predictable ways and exhibits an evolutionary trajectory. Moreover, intensive globalization has accelerated the importance of a global supply chain, global outsourcing, and global innovation performance (Könnölä et al. 2009). Related investigations in R\&D management emphasize the need for developers and users of new technologies to interact with each other to facilitate development (von Hippel 1988; Dahlander and Gann 2010). Globalization and open innovation have expedited environmental changes. Therefore, exactly how environmental changes affect the evolution of FPD industry remains uncertain. Moreover, many newly industrialized countries have entered this capital-intensive and technologically dynamic industry (Mathews 2005; $\mathrm{Hu}$ and Mathews 2005, 2008; Hu and Tseng 2007). This is despite results of a previous study which are consistent with Akamatsu's (1962) "flying geese" pattern; that is, an advanced technology from a leading country moves from country to country and from value segment to value segment. However, this systematic perspective observes, to a lesser extent, how newcomers emerge and how the incumbent market share is eroded. Therefore, evaluating how a fast-follower successfully adopts the dominant market of a first-mover is of primary concern.

Although current literature provides valuable insight into FPD technological development, many of the above questions remain unanswered. In particular, 
while these multilateral interactivity-related questions are best understood as evolutionary and network-related, few explicit social network analyses of these questions have been performed. International activity-related ideas via network analysis have been extensively adopted to study global R\&D networks (Zander 1999), the evolution of the innovator network (Cantner and Graf 2006), and global technology diffusion (Huang et al. 2011). Therefore, this study examines the network evolution framework by using network formational changes to elucidate how environmental changes influence fast-moving industrial transitions.

This study illustrates the trajectory of a fast-moving industry based on a FPD network evolution framework. FPD network formation changes in each evolutionary scenario are also examined, implying that incumbents and newcomers strategize their competitiveness. Moreover, results of this study provide relevant authorities detailed industrial trajectory data by which to devise an enhanced policy for increasing national competitiveness.

The research objectives of this study are as follows: first, the trajectory of a fastmoving industry is illustrated through a FPD-based network evolution framework. Second, FPD network formation changes are examined in each evolutionary scenario, applying incumbents and newcomers to strategize their competitiveness. Third, authority is provided to thoroughly consider the industrial trajectory in order to devise an enhanced policy for augmenting national competitiveness.

The rest of this paper is organized as follows: "Theoretical Background" reviews pertinent literature, focusing on the concept of network evolution, the technological changes in the FPD industry, as well as exogenous influences on network structural changes. "Hypotheses" then introduces the research hypotheses related to the testing of network evolution frameworks. Next, "Data and Methodology" introduces the measurements and models of social network analysis used to investigate the evolution of network formation. "Results and Discussion" also empirically tests the research hypotheses and discusses the theoretical and managerial implications. The last section finally draws the conclusions, along with recommendations for future research.

\section{Theoretical Background}

\section{Network Evolution}

Social scientists highly prioritize understanding how industrial networks evolve. Numerous scholars argue that relational behavior and network structure are linked together. An actor's relational strategy depends on a portion of the structural relationships it had previously. Meanwhile, new relationships among the actors contribute to a changed network structure that again influences its actions (Gulati and Gargiulo 1999). In this altered network structure, link formation is based on certain attachment rules. Numerous studies (Goyal et al. 2006; Uzzi and Spiro 2005; Wilhite 2001; Verspagen and Duysters 2004; Jackson and Rogers 2006) have further increased an understanding of network evolution. However, a specific industry in this context has seldom been evaluated. This study, thus, selects the FPD industry for closer examination. 
Network change comprises changes in the exit and entry of numerous actors, as well as changes in the quantities and patterns of link formation (Koka et al. 2006). A change in a structural network is a form of network change, whereas new linkages are formed with new partners. Studies on new partner searches within networks have focused mainly on two issues. One issue involves the distribution of linkages among actors in a network, which represents the inequality of access in which firms have various resources. In many real-world networks, the distribution of linkages among actors is highly unequal (Dorogovtsev and Mendes 2003; Goyal et al. 2006; Barabási et al. 2002). Barabasi and Albert (1999) posited that preferential attachment effects imply how actors accumulate new linkages proportionately to the number of linkages that they already have. In line with this "rich get richer" principle of growth, the resulting network structure comprises a few highly connected actors called stars combined with each other and many weakly connected peripheral players. Thus, this represents a basic interpretation of how an incumbent can dominate the market. The other issue occurs when a new partner search concerns the link process, which is the focus of newcomers entering and surviving in an ecological system. Therefore, a capital-intensive and fast-moving technological industry is usually evolutionary in nature. As the FPD industry demonstrates, environmental change affects the survival strategy and technological evolution of both incumbents and newcomers.

\section{Dynamic Changes of FPD Technology}

Over the last decade, the FPD industry has distinguished itself largely due to its combination of high technology and enormous capital expenditures. As a result, many FPD applications have become linked directly to daily consumer life, making it a highly promising industry for future growth. The accelerated development of FPD technology has provided advantages such as slim, lightweight, and compact shapes, energy-saving features, high image quality, enhanced visual effects, as well as a modern communication interfaces (Kawamoto et al. 2007; Stowsky 2004). Development of the FPD industry ranges from IT devices to entertainment applications, and from industrial applications to consumer electronics. With its revolutionary development, FPD technology has demonstrated its strong global potential (Murtha et al. 2001). Other than a previous study demonstrating FPD technologies passing through several phases (Kawamoto 2002), the industrial evolution of FPD has seldom been explored in the literature. Jang et al. (2009) undertook patent data research to divide the evolutionary process of FPD technologies into three periods. The first period, the predominant design stage, lasted from around 1976 to 1986 . The FPD industry that has emerged in the recent decade can trace its origin back to the 1970s and 1980s in both Japan and the United States (Florida and Browdy 1991; Brody 1996; Murtha et al. 2001). At the beginning of this stage, more than $50 \%$ of FPD patents were filed in the United States, giving it initial dominance in the industry (Jang et al. 2009). The second period, the transition stage, lasted from around 1987 to 1996 , which witnessed the establishment of the dominant design model (Jang et al. 2009). The transition stage confirmed the position of TFT-LCD as the dominant design in FPD technology, with the number of FPD patents granted worldwide more than doubling during this stage. During this stage, 
Japan accounted for more than $50 \%$ of all FPD patents granted, giving it the dominant edge in FPD technology over the US. However, few FPD patents were filed and granted in Korea and Taiwan during the middle and latter part of this transition stage. The technological divide between the incumbents Japan and the United States and the newcomers Korea and Taiwan was largely diminished when TFT-LCD emerged as the dominant design in FPD technologies (Jang et al. 2009). The third period, the postdominant design stage, lasted from around 1997 to 2005, in which triple the number of FPD patents were granted than in the transition stage (Jang et al. 2009). While Japan still retained its position as the leader in FPD technology with $50 \%$ of all FPD patents granted, Korea and Taiwan caught up with the United States to emerge as potential contenders for industry leadership.

Previous studies have focused on technological transition or knowledge dissemination more than exogenous influence on the FPD industry and formation changes (Jang et al. 2009; Kawamoto et al. 2007; Stolpe 2002). Given that the FPD industry has passed through several evolutionary phases, an evolutionary framework must be developed to analyze the strategies that different countries have adopted as they enter the industry or attempt to prolong their activities as they become incumbents in it.

\section{Exogenous Influences on Network Structural Changes}

Numerous studies focusing on structural network change have asserted that structural change occurs only after an exogenous shock (Barley 1986; Glasmeier 1991). However, exogenous influences on network evolution have seldom been addressed in the literature. Madhavan et al. (1998) investigated how a technological and regulatory event affects structural network changes. Madhavan et al. (1998) found relatively peripheral players can significantly improve their position in a loosened network structure that requires a radical change in their environment. Koka et al. (2006) devised a framework to evaluate how exogenous events affect structural network change, positing that exogenous or environmental changes are expressed in terms of changes in uncertainty and munificence, rather than specific industry events, which makes this framework feasible for general applications.

Dickson and Weaver (1997) defined uncertainty as "the inability of a firm's managers to accurately assess the external environment of the organization or the future changes that might occur in that environment." Furthermore, "uncertainty" leads to alliance activity (Nohria 1992; Powell et al. 1996). However, a previous study suggested that new alliances are used to reinforce a firm's relationships with existing partners during uncertainty (Burt 1987; Granovetter 1982; Krackhardt 1992). Furthermore, Kogut (2000) indicated that firms might form new alliances with new partners for expansion of their strategic options to eliminate uncertainty. To resolve concerns over reinforcement of existing relations or the formation of new relations with new partners, the study introduced the concept of munificence, i.e., extending available resources (regardless of whether they are plentiful or scarce) while taking into account the number of actors competing for such resources (Koka et al. 2006). Castrogiovanni (1991) defined "environmental munificence" as the extent to which critical resources exist in the environment. The degree of resource abundance in the network environment should have a significant impact on the actor's entrepreneurial 
orientation and subsequent growth. While uncertainty expands the array of actions that firms can potentially make in a changing environment, resources available to an actor limit the opportunities to do so. Therefore, this study assumes that while uncertainty presents an opportunity for forming alliances with new actors, munificence represents the ability to form alliances with new actors if the opportunity arises. This study adopts a dynamic perspective of uncertainty and munificence changes to hypothesize on the formation of network transition in the FPD industry.

Previous studies have yielded important insights in terms of industrial evolution. However, to capture processes that deal with critical changes over time can provide mature understanding for evolutional research (Parkhe et al. 2006). Meanwhile, a thorough awareness of network dynamics and the strategic actions aimed at directional change is needed (Gulati et al. 2000). This becomes a central issue when a study tries to understand how a network and its members employ internal resources and external environments to secure competitive advantage. Koka et al. (2006) provides a theoretical framework which explicitly considers network process issues and takes a more comprehensive, evolutionary perspective to consider how and under what circumstances networks can change themselves to become more effective. Restated, this framework joins changes in the attributes of external environments to patterns of changes in networks.

Koka et al. (2006) combined multiple indicators of relational behavior into four types of network change (Fig. 1). The network can churn, expand, strengthen, or shrink. Each network change is created by a specific combination of changes in tie creation, tie deletion, and by changes in an actor's portfolio size (the number of links) and portfolio range (the number of partners). Koka et al. (2006) subsequently presented four types of network change. A "churning network" reflects the formation of new alliances and the elimination of current alliances. While the average portfolio remains stable in terms of the number of partners, an increasing variety of partner identification is available. A "network expansion" is characterized by increasing its number of new alliances without eliminating old ones (implying a larger average portfolio), together with an increasing portfolio range (more different partners). A "network strengthening" is demonstrated by increasing the number of new alliances while eliminating old ones (implying a larger average portfolio), together with a decreasing portfolio range (i.e., fewer different partners). A "shrinking

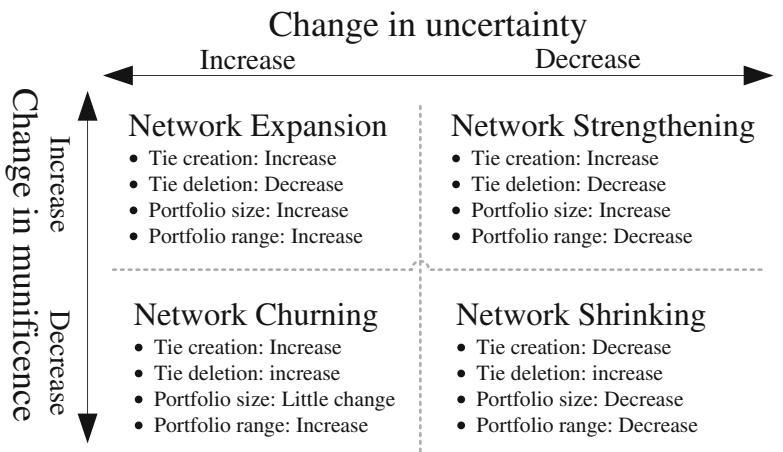

Fig. 1 Environmental effects on the patterns of network change 
network" is characterized by a decrease in new alliances with the elimination of old ones, together with a decreasing portfolio range (more different partners).

This study adopts this framework to hypothesize on the anticipated network change after a given exogenous or environmental change. Meanwhile, changes in the number of linkages (i.e., tie creation/deletion) and changes in the number of partners provide valuable insight into structural shifting in a network.

\section{Hypotheses}

The hypotheses in this study draw upon the network evolution framework of Koka et al. (2006) to examine FPD technology network transitions. Although Koka et al. asserted this evolutionary framework without indicating a trajectory between each scenario, this study identifies a trend in environmental changes as environmental munificence gradually increases and environmental uncertainty gradually decreases, as well as changes trajectory from network churning, network expansion and then network strengthening. Furthermore, this study also draws upon Jang et al. (2009) to classify the FPD technologies' evolutionary process into three periods, i.e., predominant, transition, and postdominant. We, thus, posit the following hypotheses based on Koka's evolution framework, i.e., formation of network churning to network strengthening scenarios.

Koka et al. (2006) asserted that an industrial environment is less predictable and fewer resources are available (i.e., the network faces increasing uncertainty and decreasing munificence), often creating opportunities for some companies to improve their positioning but threatening those for others who may lose their market share. Under such circumstances, increases in both interorganizational tie formation and interorganizational tie deletion only slightly change the portfolio size and decrease the portfolio range. We posit the following hypotheses for Environment I scenarios:

Hypothesis 1: under environmental conditions of increasing uncertainty and decreasing munificence, FPD industry demonstrates network churning.

Hypothesis 1a: networks decrease in terms of the number of new tie creations.

Hypothesis 1b: networks increase the number of tie deletions.

Hypothesis 1c: networks only slightly change in terms of portfolio size.

Hypothesis 1d: networks increase in terms of the range of tie portfolios.

An industry undergoing a flurry of activity involves both newcomers and incumbents since the environment remains less predictable and more resources are available, i.e., the network increases in uncertainty and increases in munificence. Under such circumstances, increased network tie formation and decreased tie deletion increase in both portfolio size and range. We, thus, posit the following hypotheses for Environment II scenarios:

Hypothesis 2: under the environmental conditions of an increasing uncertainty and an increasing munificence, the FPD industry expands its network. 
Hypothesis 2a: networks increase the number of new tie creations.

Hypothesis 2b: networks decrease the number of tie deletions.

Hypothesis 2c: networks increase the size of tie portfolios.

Hypothesis 2d: networks increase the range of tie portfolios.

Consider a situation in which an environment is more predictable and more resources are available, i.e., the network potentially decreases in uncertainty and increases in munificence. Under such conditions, a network increases tie formation more than existing partners and decreases tie deletions, with an increase in terms of portfolio size and a decrease in terms of range (Koka et al. 2006). We, thus, posit the following hypotheses for Environment III scenarios:

Hypothesis 3: under environmental conditions of decreasing uncertainty and increasing munificence, the FPD industry demonstrates a strengthening network.

Hypothesis 3a: networks increase the number of new tie creations.

Hypothesis 3b: networks decrease the number of tie deletions.

Hypothesis 3c: networks increase the size of tie portfolios.

Hypothesis 3d: networks decrease the range of tie portfolios.

\section{Data and Methodology}

Data

In addition to providing strategic background information regarding nation-specific and sector-specific factors in domestic and global science-technology linkages and knowledge flows (Tijssen 2001), patent citation network analysis demonstrates a technological transition regarding industry-specific development. This study, thus, utilizes FPD patent document keyword search using the United States Patent and Trademark Office (USPTO) database. Appendix A-1 provides a specific keyword list. To empirically examine their network relationships, a base sample of 23,903 FPD patent documents were compiled to obtain 248,728 patent citation records from 71 countries from 1976 to 2008. Appendix A-2 provides a country-specific list. However, evaluation of environmental munificence utilizes the Datastream Global Equity databank. The Datastream indices have an extremely broad coverage of stocks within markets for the electronics industry and are easily compared across countries. Datastream market indices are also available for a broad set of countries, thus providing an ideal source for our analysis of the FPD industry. Datastream indices are also characterized by their detailed sectoral indices on the electronics capital market. The empirical analysis is based on annual financial market data, in which closing quotes in US dollars of the respective national stock markets are used.

\section{Methodology}

This study adopts the network evolution model of Koka et al. (2006) to investigate the network transition patterns of FPD technology, as follows. 


\section{Environmental Munificence}

Numerous scholars (Amit and Zott 2004; Castrogiovanni 1991; Dess and Beard 1984; Staw and Szwajkowski 1975) have developed an environmental munificence measure based on capital markets. Restated, the trends of industry averages Return On Investment (ROI) and Return On Equity (ROE) can represent munificence change. Park and Mezias (2005) identified the National Association of Securities Dealers Automated Quotations (NASDAQ) index as the most reliable proxy of environmental munificence in the electronics industry. This study, thus, utilizes the average stock price to evaluate environmental munificence. Moreover, the electronics market of the leading countries in the FPD industry, i.e., the United States, Japan, Taiwan, and South Korea, respectively (Jang et al. 2009), have been selected for investigation. Appendix B provides further details. The electronics stock market demonstrates difference percentages for the economic performance of the above countries. Their global FPD patent percentage is, thus, referred to here as weight percentage. That is, Eq. 1 is expressed as:

$$
\text { munificence }_{t}=E\left(\alpha P_{U S, t}+\beta P_{J P, t}+\gamma P_{T W, t}+\theta P_{K R, t}\right) .
$$

In Eq.1, FPD industry munificence for year $t$ is the expected value of electronic stock price for the four countries, i.e., $P_{U S, t}, P_{J P, t}, P_{T W, t}$, and $P_{K R, t}$; in addition, the four countries contribute different weights $\alpha, \beta, \gamma$, and $\theta$ to FPD industry munificence.

\section{Environmental Uncertainty}

Network centralization (or global centrality) refers to the extent to which an entire network focuses around a few central nodes (Scott 1991). This is especially relevant for an interorganizational study of coordination and leadership. Turk (1977) posited that interagency network centralization can be correlated with coordination. Similarly, Tichy (1980) defined global network centrality as the extent "to which relations are guided by the formal hierarchy," while Irwin and Huges (1992) referred to network centralization as the degree to which an interorganizational network is "dominated by a few places." Therefore, as an industry remaining in a predominated environment, the network should observe a lower degree of centralization. Restated, in an environment with higher technological uncertainty, lower levels of global centrality should be expected. The equation of environmental uncertainty can, thus, be formulated as:

$$
\text { uncertainty }_{t}=\frac{1}{\text { centralization }_{t}} .
$$

Here, uncertainty $_{t}$ denotes the extent of inverse centralization in year $t$, where centralization is formulated as: $\sum_{i=1}^{n}\left(C_{R D \max }-C_{R D i}\right) /(n-2)$. The $C_{R D i}$ represents the relative centrality in a network composed of $n$ actors and the $C_{R D \max }$ represents the maximum value of relative centrality (Degenne and Forsé 1999). 


\section{Network Formation}

This study evaluates four network features by using the network evolution framework of Koka et al. (2006). First, network tie creation and tie deletion can be formulated as:

$$
\begin{aligned}
& \text { Tie Creation } t=E_{i}\left(\sum_{q} Z_{i q, t} \mid Z_{i q, t}>Z_{i q, t-1}\right), i \neq q \\
& \text { Tie Deletion }_{t}=E_{i}\left(\sum_{q} Z_{i q, t} \mid Z_{i q, t}<Z_{i q, t-1}\right), i \neq q .
\end{aligned}
$$

In Eqs. 3 and 4, the tie creation measurement, $Z_{i q, t}$ denotes the actor $i$ patent citing value at year $t$; if this value is larger than year $t-1$, it can be identified as tie creation. On the other hand, a situation in which the $Z_{i q, t}$ value is less than $Z_{i q, t-1}$, it can be regarded as a tie deletion. The summation is the sum of actor $i$ to all other actors. Then, the expected value $E_{i}$ denotes the average extent of network tie creation at year $t$.

Second, for the network portfolio size and portfolio range measurement, the equation of portfolio size is defined as:

$$
\text { Portfolio Size }_{t}=E_{i}\left(\sum_{q} S_{i}=1 \mid Z_{i q, t} \neq 0 \text { or } Z_{q i, t} \neq 0\right), i \neq q
$$

where $Z_{i q, t}$ or $Z_{q i, t}$ denotes actor $i$ and actor $q$ in citation relation at year $t$. Also, $S_{i}=1$ denotes that the actor $i$ increases by one linkage. The summation is the sum of actor $i$ to all other actors. The expected value $E_{i}$ denotes the average extent of portfolio size at year $t$.

For the portfolio range measurement, Koka et al. (2006) addressed network portfolio range as the heterogeneous nature of a network. Therefore, this study can observe the extent of an actor developing a new partnership as a portfolio range measurement. The equation is defined as:

$$
\text { Portfolio Range }_{t}=E_{i}\left(\sum_{q} S_{i}=1 \mid A \text { or } B\right), i \neq q
$$

where, $A=\left(Z_{i q, t-1}=0\right.$ and $\left.Z_{i q, t}>0\right), B=\left(Z_{q i, t-1}=0\right.$ and $\left.Z_{q i, t}>0\right)$. The condition $A$ or $B$ represents actor $i$ and actor $q$ increase new citation relation at year $t$. Therefore, $S_{i}=1$ denotes the actor $i$ developing a new partnership. The summation is the sum of actor $i$ to all other actors. The expected value $E_{i}$ denotes the average extent of portfolio range at year $t$.

\section{Network Transition Via Environmental Changes}

Koka et al. (2006) integrated multiple indicators of relational behavior into patterns of network change. A network can expand, churn, strengthen, or shrink. Each network change arises not only from a unique combination of changes in tie creation and tie 
deletion, but also by changes in an actor's portfolio size, i.e., number of links, and portfolio range, i.e., number of partners. This study, thus, formulates the distinctive network formation via environmental change as:

$$
Y_{t}=\beta_{0}+\beta_{1} \text { Env } N+\varepsilon, E n v \_N=\text { Environment } I, I I, I I I .
$$

Here, $Y_{t}$ denotes network formation at year $t$ which includes Tie Creation , Tie Deletion $_{t}$, Portfolio Size , and Portfolio Range $_{t}$. On the other hand, dummy variable $E n v \_N$ denotes three environmental scenarios which include Environment I, II, and III. Each scenario represents environmental change. Therefore, this study expresses the condition below:

$$
\begin{gathered}
\text { Environment I }=\left\{\begin{array}{l}
1, \text { Munificence in 1976 } 1988, \\
0, \text { otherwise }
\end{array}\right. \\
\text { Environment II }=\left\{\begin{array}{l}
1, \text { Munificence in } 1989 \sim 1997 \\
0, \text { otherwise }
\end{array},\right. \\
\text { Environment III }=\left\{\begin{array}{l}
1, \text { Munificence in } 1998 \sim 2008 \\
0, \text { otherwise }
\end{array}\right.
\end{gathered}
$$

\section{Results and Discussion}

This study demonstrates that environmental changes affect network formation. The research hypotheses were tested via regression analysis based on four network characteristics, i.e., network tie creation, deletion, and portfolio size and range. Figure 2 shows the longitudinal tendency of environmental changes, while Fig. 2a, b, and c shows

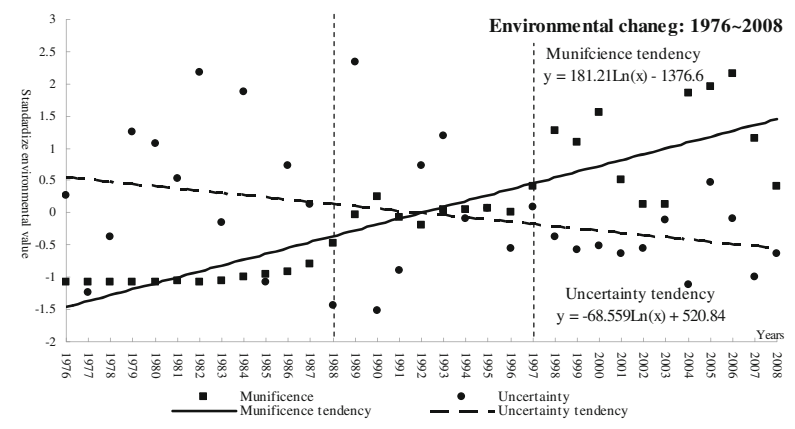

a $1976 \sim 1988$

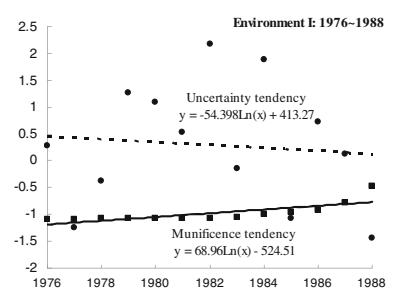

b $1989 \sim 1997$

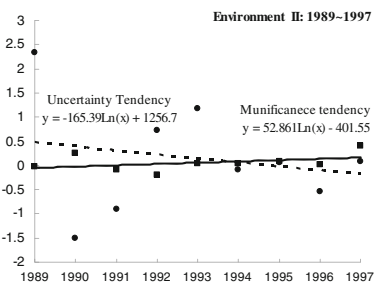

C $1998 \sim 2008$

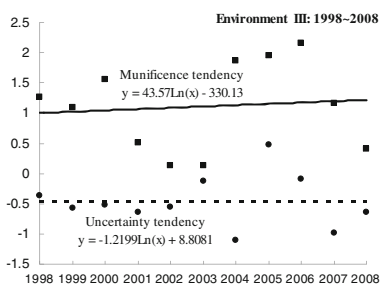

Fig. 2 The tendency of environmental munificence and uncertainty: 1976-2008 
Table 1 Network evolution via environment change

\begin{tabular}{|c|c|c|c|c|c|c|c|c|c|c|c|c|}
\hline \multirow{2}{*}{$\begin{array}{l}\text { Network } \\
\text { Environment }\end{array}$} & \multicolumn{3}{|c|}{ Tie creation } & \multicolumn{3}{|c|}{ Tie deletion } & \multicolumn{3}{|c|}{ Portfolio size } & \multicolumn{3}{|c|}{ Portfolio range } \\
\hline & I & II & III & I & II & III & I & II & III & I & II & III \\
\hline$\beta$ coefficient & 0.667 & 0.859 & 0.691 & 0.504 & 0.837 & 0.725 & 0.539 & 0.822 & 0.547 & 0.769 & 0.146 & -0.320 \\
\hline$p$ value & 0.018 & 0.003 & 0.018 & 0.094 & 0.005 & 0.012 & 0.057 & 0.007 & 0.081 & 0.003 & 0.708 & 0.344 \\
\hline Observations & 2,272 & 2,272 & 2,272 & 2,272 & 2,272 & 2,272 & 2,272 & 2,272 & 2,272 & 2,272 & 2,272 & 2,272 \\
\hline
\end{tabular}

period tendency. Table 1 summarizes network formational changes via three environmental scenarios.

\section{Environment I (1976-1988)}

According to the empirical results in Table 1, the network coefficients indicate a positive trend where Hypotheses 1a, 1b, and 1d are valid. However, Hypothesis $1 \mathrm{c}$ is not valid. More specifically, according to our results, four networking coefficients are positive in Environment I. In comparison with the Koka framework, this finding slightly differs in terms of network portfolio size. Thus, this finding partially supports Hypothesis 1. The FPD technological network in this scenario not only exhibits growth in terms of tie creation and deletion, but also demonstrates an increasing portfolio size and range of terms. We can, thus, infer that the FPD network is both churning and slightly expanded. Restated, the FPD industry has already attracted the participation of many countries in this stage of development. However, as each country has differing levels of technological competency, when their international cooperation cannot generate synergy or a more complementary asset, the cooperative link shifts to another country, resulting in an unstable network configuration. Furthermore, Koka et al. (2006) suggested that networks only slightly change in portfolio size, without providing further detail into the extent of the change. Our results further indicate that the portfolio size, i.e., number of links, is positive and has only a slight significance. We can, thus, infer that each country attempts to match its collaborators' resource, subsequently increasing the number of links. As for the formation of new linkages, Gulati (1998) found that new tie creation is heavily embedded in the existing network. We can, thus, infer that new ties are often formed with previous partners or with partners of previous partners, where strategic collaborations are path-dependent (Nohria 1992). New link formation is considered risky, and actors prefer alliances embedded in a dense clique and function as norms that are more likely to be enforceable and in which opportunistic behavior is to be punished (Gulati 1998; Powell et al. 1996; Granovetter 1992).

Between 1976 and 1988, environmental munificence remained at the initial stage; commercial electronic products emerged from a specific market (Fig. 2a). Thus, resource munificence demonstrates a low status. However, FPD technology presents itself as a new opportunity to many industrial countries, explaining their aggressive efforts in this new frontier. In the mid-1970s, the previous technology (dynamic scattering mode, DSM-LCD) designs faded dominance, subsequently explaining the 
increase in the number of tie deletions. However, mainstream FPD technology is twisted nematic (TN) display technology However, in the early 1980s, TN technology began transitioning to super-twisted nematic (STN) display technology. Previous TN alliances transformed into STN technology, creating an increase in the number of links during this period.

\section{Environment II (1989-1997)}

According to Environment II in Table 1, four network coefficients show positive results, inferring that Hypotheses 2a, 2c, and $2 \mathrm{~d}$ are supported yet Hypothesis $2 \mathrm{~b}$ is not. Koka et al. (2006) suggested that for the scenarios involving abundant resources and unpredictable circumstances, decision-makers attempt to strengthen their original partnerships and recruit new partners. The network is, thus, characterized as having increased its linkage (i.e., increase in tie creation) and not having eliminated previous links (i.e., decrease in tie deletion). Meanwhile, the numbers of partners (i.e., portfolio size) and network heterogeneity (i.e., portfolio range) are increased. However, our results found some inconsistencies with those of previous studies. First, increases in network tie deletions remain. That is, the coefficient of tie deletion is positive and significant in Environment II. Second, the portfolio range increased insignificantly. This finding partially supports Hypothesis 2 . Network changes along with tie creation and tie deletion increased simultaneously. We can, thus, infer that the FPD industry in these networks accounts for the dominant form of technology competition. Burt (1992) asserted that actors should spend time and energy in maintaining their existing linkage, meaning that a linkage must be decided upon based on mutual benefits or compatible recourse. However, because a previous partnership has developed individual capabilities and specific assets, these partnerships tend to develop complementary linkages. Therefore, the heterogeneity of a network (portfolio range) only slightly increases.

Environment II remained in uncertainty (Fig. 2b), explaining why countries will not be eliminated entirely with a previous partnership. In the late 1980s, Japan dominated STN design technology and successfully transitioned from monochrome to color STN. During that period, Japan became the incumbent of the FPD industry. However, in the early 1990s, FPD technologies elevated to a higher stage; STN display technology transitioned to thin film transistor (TFT) display technology. Notably, TFT-LCD primary components, linkages, design concepts, and functions in products stemming from the technological developments of TFT technology differed from those during the earlier development of STN. Thus, in the mid-1990s, Japan licensed a previous technology and original equipment manufacturing from neighboring countries, e.g., Korea and Taiwan, to acquire any residual value from STN technology. Thus, network changes during this period not only demonstrated that Japan strategically transferred their technology to newcomers, but also exhibited dominant design translation. Accordingly, by the mid-1990s, FPD patents granted to newcomers South Korea and Taiwan were more likely to be cited from Japanese patents rather than US ones (Jang et al. 2009) (see Appendixes C-2 and C-3). This finding suggests that newcomers began developing a compatible technology to aggregate complementary assets in FPD technology. More specifically, the Industrial Technology Research Institute developed TFT-LCD capabilities under the auspices of the Ministry of Economic Affairs in Taiwan. Meanwhile, Korea acquired TFT technology without licensing it from 
Japanese incumbents (Mathews 2005). In the late 1990s, TFT-LCD became a critical component in information and communication technology (ICT) products. However, the Asian financial crisis of 1997 disrupted market domination by the Japanese.

\section{Environment III (1998-2008)}

According to empirical results during this period, although the coefficient of tie creation, tie deletion, and portfolio size positively increased, the portfolio range negatively decreased. Thus, Hypotheses $3 \mathrm{a}, 3 \mathrm{c}$, and $3 \mathrm{~d}$ are validated yet Hypothesis $3 \mathrm{~b}$ is not. Hypothesis 3 is, thus, partially supported. Koka et al. (2006) suggested that during this period of stable market conditions and decreased uncertainty, organizations in mature industries expanded quickly with an increasing amount of resources available to them (Fig. 2c). Most organizations are connected with each other through simple partnerships, sharing technologies to mass produce identical products and a pattern of imitation between competitors that tends to result in constrained portfolio ranges. Organizations strengthened their ties with current partners to block out newcomers, explaining why tie creation increased and deletion decreased, ultimately increasing portfolio sizes. However, an increase in network changes along with simultaneous tie creation and tie deletion is inconsistent with results of a previous study (Koka et al. 2006).

In addition to succumbing to domestic financial pressure after the Asian financial crisis of 1997, Japan also encountered South Korean competition. Japan, thus, reinforced its Taiwan alliances to control costs and increase productivity. Restated, in the early 2000s, Korea heavily invested in fourth-generation TFT-LCD fabrication equipment and developed various applications; from ICT products to new applications in consumer electronic products such as portable media players, flat panel TVs, and digital still cameras, thus challenging Japan incumbents (Mathews 2005). Therefore, in the late 1990s, Japanese firms began licensing related technologies to Taiwan partners, with Taiwan joining in 4G TFT-LCD manufacturing in the early 2000s. Therefore, the simultaneous increase in tie creation and tie deletion demonstrated the ability of the FPD incumbents to enhance their productivity. This finding also indicates that the FPD industry culminates in quantitative competition. Furthermore, a new FPD entry barrier was posed, in which network heterogeneity (portfolio range) decreased. In the mid-2000s, Korea and Taiwan became incumbents, while emerging industrialized countries are now the challengers.

\section{Evolutionary Trajectory of FPD Industry}

Along with network churning, network expansion to network strengthening scenarios, regression analysis reveals that the tie creation and tie deletion are positive and significant. This finding suggests that the FPD industry has continuously evolved along with environmental changes, while a technological coevolution has occurred in industrial East Asian countries (Stolpe 2002). In particular, the above technological developments demonstrate a trajectory with international interactivity. Therefore, the longitudinal FPD network change patterns are shown in Fig. 3.

During the network churning period, FPD technology in industrialized countries provided innovation and led to a dominant design. This result implies industrialized countries hold an early technological advantage. First-mover advantages were founded 


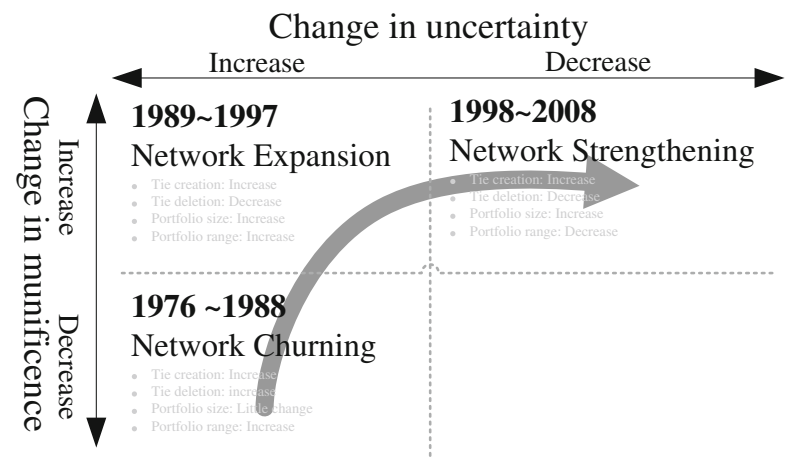

Fig. 3 Longitudinal network change trajectory in the FPD industry: 1976-2008

upon their technological innovation and demonstrated their national innovative capacities. Therefore, Japan and the US demonstrated qualitative competition in terms of dominant FPD design. During the network expansion period, Japan became the incumbent, with abundant FPD assets during the early period and then strategically recruiting newcomers from newly industrialized countries to eliminate risks in mass production after the middle period. This result suggests environmental changes affect international technology diffusion; newly industrialized countries begin acquiring FPD-related technology and develop a local FPD industry. Therefore, the patents awarded to Korea and Taiwan showed a large citation percentage from Japan and the US. Appendix C-2 provides further details. During the network strengthening period, investment by Korea and Taiwan in 4G TFT-LCD fabrication equipment implies environmental change toward a decreasing technological uncertainty. Meanwhile, the number of patents awarded to Korea and Taiwan grew rapidly (see Appendix D). This result implies fast-followers not only demonstrate their technological progress in manufacturing advantages but also exhibit culmination in quantitative competition within the FPD industry. This evolutionary trajectory implies that different environmental scenarios provide newcomers different options for developing their technological niche capability. Despite extremely high market entry barriers to the FPD industry, such barriers have been breached. Policy-makers realigned their science and technology policies; reallocating their international cooperation (Huang et al. 2011) and national innovation systems (Hu and Tseng 2007) for specific industrial capabilities. This finding provides implications for policy-makers and business practitioners involved in dynamic and competitive global industries similar to FPD.

\section{Conclusions}

Environmental change affects incumbents and newcomers not only in terms of their survival strategies, but also in their technological evolution. This study has demonstrated this change on the FPD sector, a capital-intensive and fast-moving technology industry that has witnessed the successive entries of Japan, Korea, and Taiwan in recent decades. Owing to the difficulty of comparative analytical frameworks in providing a dynamic perspective for this fast-growing industry, this study explored the FPD industry by using a network evolutionary framework. 
Based on changes in electronic stock markets as an environmental munificence as well as changes in technological network centrality as an environmental uncertainty, this study investigated the central role of network evolution in the FPD industry. The two mechanisms were then successfully applied to study the network evolution of the industry. Furthermore, based on the empirical results, this study identified a distinguishable evolution pattern for each scenario of environmental change.

First, under environmental conditions of an increase in uncertainty and a decrease in munificence, the FPD industry underwent an unstable interaction in technology development. Thus, the formation of network churning implies technological exploration via global activity. Under the environmental conditions of an increase in uncertainty and an increase in munificence, the FPD industry demonstrated its competitiveness in design dominance and extension of FPD applications. Thus, network expansion formation suggests that incumbents expand their strategies through international alliances. Under the environmental conditions of a decrease in uncertainty and an increase in munificence, the FPD industry demonstrated its competitiveness in productive efficiency and strategic collaboration with newcomers. Thus, the formation of network strengthening implies that incumbents reintegrate their international resources for quantitative competition. The development of FPD technologies has not only demonstrated a technological extension in product application terms, but also exhibited technological competitiveness in national innovative capacity (Hu and Tseng 2007). Restated, network changes via environmental uncertainty and environmental munificence changes affect the ability of the FPD industry to shift from special devices to electronic consumer products. Meanwhile, the evolutionary trajectory of FPD technologies has shifted from qualitative competition to quantitative competition. Thus, this finding correlates with the product realization process (Betz 2003). Still, international technological competition is another major driving engine of advancement in FPD technology.

Second, Japan and the United States have demonstrated first-mover strategies. The US pioneered FPD technology in the early 1970s, followed by technological competitiveness between itself and Japan, as evidenced by the rate of patents granted to each country and their patent source percentage in domestic technologies. However, as the number of Japan patents grew rapidly, the US exhibited a slower rise, culminating in a gentle decline after 2000. Appendix D provides further details. Additionally, fastfollowers Korea and Taiwan changed their technological source to Japan. Although the United States was the early leader in FPD technology, Japan successfully achieved dominant design in the late 1980s. While accelerating FPD technological diversification and constructing entry barriers, Japan doubled the number of patents granted to it and demonstrated a high local content rate in its patent self-citation percentage. Appendix C provides further details. However, in 2004, Japan underwent a patent grant decline (see Appendix D). This finding suggests that Japan has gradually faded from dominant FPD design. On the other hand, as demonstrated by the follower strategies of Korea and then Taiwan, extremely high market entry barriers to the FPD industry have been breached. In the early 1990s, Korea and Taiwan appeared as fast-followers through mergers or licensing from previous US technologies to enter the FPD industry. Thereafter, these newcomers accelerated the next network transition. As a result, FPD industrial evolution demonstrated network expansion. In the late 1990s, despite participation of incumbent Japan through international cooperation to cope with environmental changes, Korea and Taiwan achieved an effective national 
innovation system (Hu and Tseng 2007; Hu and Mathews 2005; Chang and Shih 2005), achieving dominance in the FPD industry in the mid-2000s. This finding suggests that newcomers can enter a fast-moving industry depending not only on their national innovativeness, but also on their international cooperation network. Korean authorities reformed their Chaebol system (conglomerate) (Hobday et al. 2004) after the Asian financial crisis and reinforced their alliances with the Netherlands and the United States to develop 4G fabrication capabilities. Korea has accelerated entry barriers not only through their rapidly growing patent acceptance rates, but also through a high local content rate, as exhibited on their country patent citation percentage. Appendix $\mathrm{C}$ provides further details. However, Taiwan has demonstrated a different approach in the development of FPD technology. According to Taiwan FPD country patent citation percentages (see Appendix C), the leading four FPD manufacturing countries maintain a fair distribution. That is, in addition to diversifying their technological sources, decentralized technological development in Taiwan also demonstrates industrial development. Several domestic interindustrial clusters (Hu and Tseng 2007) and multinational cooperation efforts have shaped this unique feature. Taiwan has diversified its technological cooperation alliances, acquiring FPD technology primarily from the US rather than Japan to aggregate and integrate its competency (Chu 2009). However, in comparison with Korea's high self-citation rates, technological independence in Taiwan is based on international cooperation, while Korea's is less so.

Finally, this study finds that industrial development of FPD demonstrates a trajectory with multinational interactivity; during the network churning period, FPD technology demonstrates how industrialized countries provide essential technologies to explore new territories. During the network expansion period, Japan was the incumbent with abundant FPD-specific assets early on and then strategically recruited newcomers from newly industrialized countries to eliminate risk in mass production after environmental transition. During the network strengthening period, new incumbents Taiwan and Korea demonstrated quantitative competition in FPD productivity. The FPD industry has evolved along environmental changes, while East Asian countries have undergone industrialization in a technologically coevolutionary model. Furthermore, this evolutionary trajectory suggests that policy-makers can strive to identify how industrial networks evolve and strategize their competitiveness. As a dynamic and capitalintensive global industry, the global FPD industry has provided competent newcomers with opportunities to acquire and cultivate related technologies to gain a foothold first and to become strong players later, while environmental scenarios appear to show qualitative competition based on dominant design, early industrialized countries hold a technological advantage. While the evolutionary trajectory has shifted from qualitative competition to quantitative competition within the industry, newly industrialized countries demonstrate a manufacturing advantage. Different environmental scenarios provide newcomers opportunities to develop niche competence. Policy-makers can seize opportunity for entry via science and technology policy realignment; reallocating their international cooperation and national innovation system for specific industrial purposes to accumulate technological competence. Therefore, this finding provides implications for policy-makers involved in dynamic and competitive global industries similar to FPD.

Despite its contributions, this study has certain limitations, which should be acknowledged to identify future research directions. First, Korea and Taiwan have adopted different industrial development strategies. Through the Chaebol system, 
Korea has advanced its technology capacity. Meanwhile, Taiwan has utilized a decentralized industrial system to aggregate technology capacity. Whether this difference in systems affects quantitative competitiveness remains unclear. Second, in the late 2000s, the new challengers China and India appeared. Whether those newcomers can evoke extended network changes is uncertain. Third, Korea and Taiwan incumbents, and previous incumbents Japan and the United States, continue to develop advanced FPD technologies. Whether or not new technologies can become dominant also remains uncertain. Finally, this study focuses on the FPD patent citation network to the exclusion of other social network analyses. Future research should apply more social network analysis-related indicators and concepts.

Open Access This article is distributed under the terms of the Creative Commons Attribution License which permits any use, distribution, and reproduction in any medium, provided the original author(s) and the source are credited.

\section{Appendix A}

Table 2 FPD technologies and keywords used for patent search

\begin{tabular}{ll}
\hline Technology domain & Keywords \\
\hline LCD: liquid crystal display & Liquid crystal display, LCD \\
TN \& STN: super-twisted nematic & $\begin{array}{l}\text { Twisted nematic, super twisted nematic, TN, STN, TN-LCD, } \\
\text { STN-LCD }\end{array}$ \\
TFT: thin film transistor & Thin film transistor, TFT, TFT-LCD \\
LTPS: low-temperature poly-silicon & Poly silicon, p-si, poly-si, low temperature poly silicon, LTPS \\
PDP: plasma display panel & Plasma panel, plasma display panel, PDP \\
EL: electroluminescence & \\
LED: light emitting diode & Light emitting diode \\
OEL: organic electroluminescence & Organic electroluminescence, OEL, OLED \\
\hline
\end{tabular}

Source: Jang et al. (2009)

\section{Appendix A-2}

Table 3 Countries of FPD technology patents

$\begin{array}{ll}\text { AG, } & \text { Antigua and Barbuda } \\ \text { AN, } & \text { Netherlands Antilles } \\ \text { AR, } & \text { Argentina } \\ \text { AT, } & \text { Austria } \\ \text { AU, } & \text { Australia } \\ \text { BB, } & \text { Barbados } \\ \text { BE, } & \text { Belgium }\end{array}$


Table 3 (continued)

\begin{tabular}{|c|c|}
\hline $\mathrm{BG}$ & Bulgaria \\
\hline BM, & Bermuda \\
\hline $\mathrm{BO}$, & Bolivia \\
\hline $\mathrm{BR}$ & Brazil \\
\hline BY, & Belarus \\
\hline $\mathrm{CA}$, & Canada \\
\hline $\mathrm{CH}$, & Switzerland \\
\hline $\mathrm{CN}$ & China \\
\hline $\mathrm{CS}$ & Czechoslovakia (former) \\
\hline $\mathrm{DE}$, & Germany \\
\hline $\mathrm{DK}$, & Denmark \\
\hline EG, & Egypt \\
\hline $\mathrm{ES}$ & Spain \\
\hline FI, & Finland \\
\hline FR, & France \\
\hline GB, & Great Britain (UK) \\
\hline GR, & Greece \\
\hline HK, & Hong Kong \\
\hline $\mathrm{HU}$ & Hungary \\
\hline ID, & Indonesia \\
\hline IE, & Ireland \\
\hline IL, & Israel \\
\hline IN, & India \\
\hline IS, & Iceland \\
\hline IT, & Italy \\
\hline $\mathrm{JO}$, & Jordan \\
\hline $\mathrm{JP}$ & Japan \\
\hline $\mathrm{KN}$, & Saint Kitts and Nevis \\
\hline $\mathrm{KP}$, & Korea (North) \\
\hline $\mathrm{KR}$, & Korea (South) \\
\hline $\mathrm{KW}$ & Kuwait \\
\hline $\mathrm{KY}$, & Cayman Islands \\
\hline LI, & Liechtenstein \\
\hline LU, & Luxembourg \\
\hline $\mathrm{MC}$ & Monaco \\
\hline MM, & Myanmar \\
\hline MX, & Mexico \\
\hline MY, & Malaysia \\
\hline NI, & Nicaragua \\
\hline NL, & Netherlands \\
\hline $\mathrm{NO}$ & Norway \\
\hline $\mathrm{NZ}$ & New Zealand \\
\hline PA, & Panama \\
\hline PE, & Peru \\
\hline
\end{tabular}


Table 3 (continued)

\begin{tabular}{ll}
\hline PH, & Philippines \\
PK, & Pakistan \\
PL, & Poland \\
PT, & Portugal \\
RO, & Romania \\
RU, & Russian Federation \\
RW, & Rwanda \\
SA, & Saudi Arabia \\
SE, & Sweden \\
SG, & Singapore \\
SI, & Slovenia \\
SU, & USSR (former) \\
TH, & Thailand \\
TR, & Turkey \\
TW, & Taiwan \\
US, & United States \\
VE, & Venezuela \\
VG, & British Virgin Islands \\
YU, & Yugoslavia (former) \\
ZA, & South Africa \\
\hline
\end{tabular}

Order by ISO 3166-1-alpha-2 code. Source: http://www.iso.org/ and USPTO

\section{Appendix B. Global FPD patent grants}

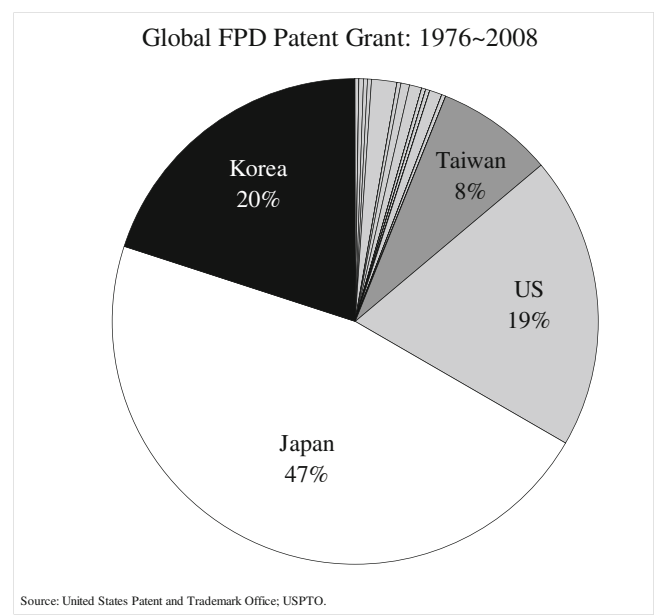


Appendix C. Country patent citations of major FPD manufacturing nations 1976-2008
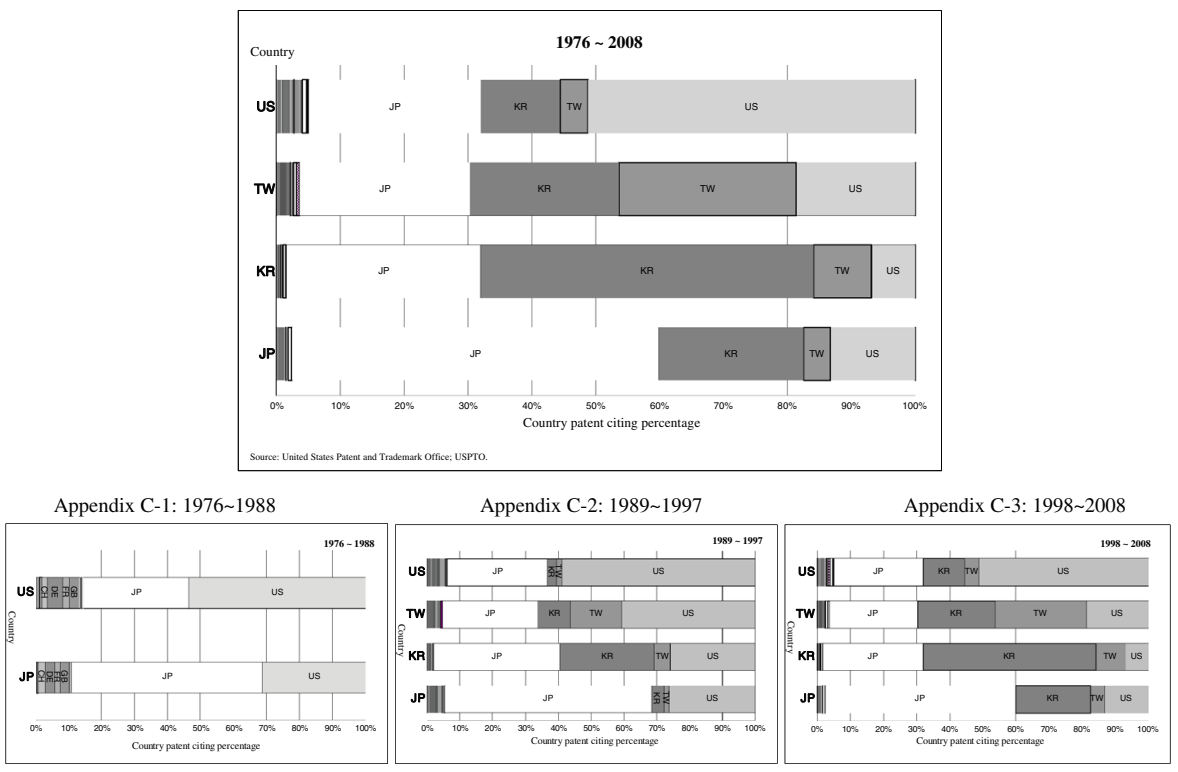

Appendix D. Patent grant tendency in the FPD industry 1976-2008. Source: United States Patent and Trademark Office (USPTO)

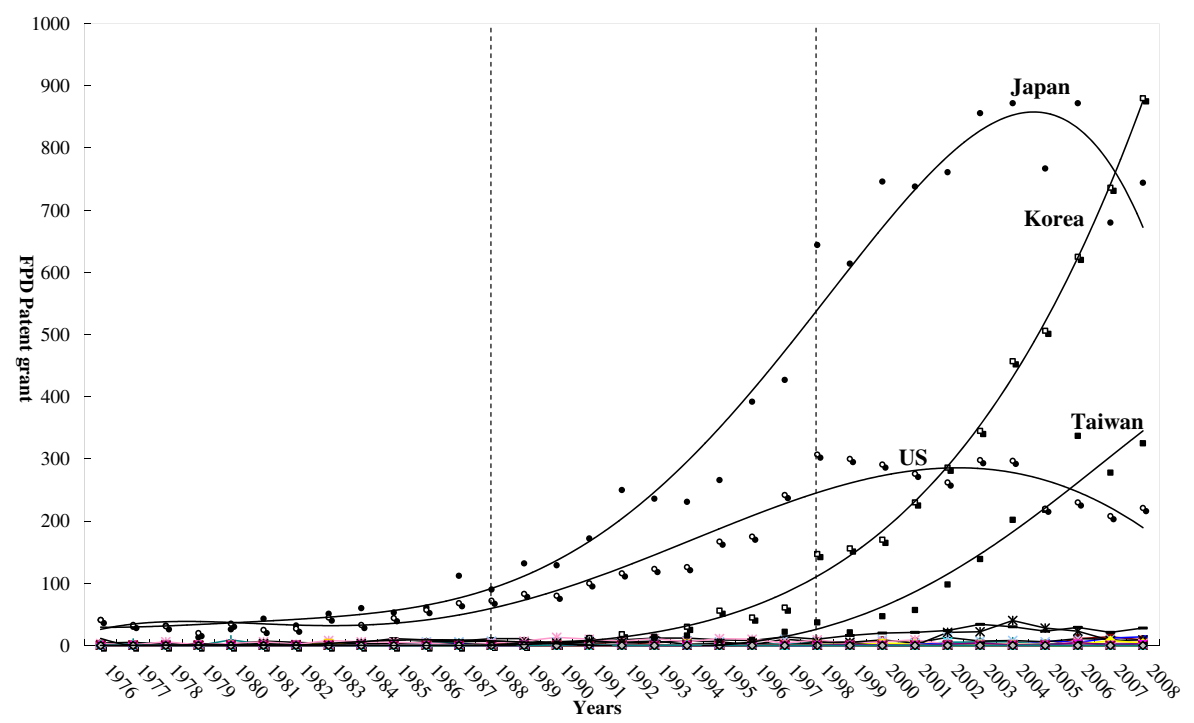




\section{References}

Akamatsu, K. (1962). A historical pattern of economic growth in developing countries. The Developing Economies, 1, 3-25. Mar-Aug.

Amit, R., \& Zott, C. (2004). Global equity capital markets for emerging growth firms: Patterns, drivers, and implications for the globalizing entrepreneur. (The Alliance on Globalizing): Cambridge University Press.

Barabasi, A.-L., \& Albert, R. (1999). Emergence of scaling in random networks. Science, 286, 509-512.

Barabási, A.-L., Jeong, H., Neda, Z., Ravasz, E., Schubert, A., \& Vicsek, T. (2002). Evolution of the social network of scientific collaborations. Physica A: Statistical Mechanics and its Applications, 311, 590614.

Barley, S. R. (1986). Technology as an occasion for structuring: Evidence from observations of CT scanners and the social order of radiology departments. Administrative Science Quarterly, 21(1), 78-108.

Barro, R. J., \& Sala-i-Martin, X. (1997). Technological diffusion, convergence, and growth. Journal of Economic Growth, 2(1), 1-26.

Betz, F. (2003). Managing technological innovation-Competitive advantage from change (2nd ed.). New York: Wiley.

Brody, P. T. (1996). The birth and early childhood of active matrix: A personal memoir. Journal of the Society for Information Display Apr, 113-127.

Bruno, A. V., \& Tyebjee, T. T. (1982). The environment for entrepreneurship. In C. A. Kent, D. L. Sexton, \& K. H. Vesper (Eds.), Encyclopedia of entrepreneurship (pp. 288-307). Englewood Cliffs: Prentice-Hall.

Burt, R. S. (1987). Social contagion and innovation, cohesion versus structural equivalence. The American Journal of Sociology, 92, 1287-1335.

Burt, R. S. (1992). Structural holes: The structure of competition. Cambridge, MA: Harvard University Press.

Cantner, U., \& Graf, H. (2006). The network of innovators in Jena: an application of social network analysis. Research Policy, 35(4), 463-480.

Castrogiovanni, G. J. (1991). Environmental munificence: a theoretical assessment. Academy of Management Review, 16, 542-565.

Chang, P.-L., \& Shih, H.-Y. (2005). Comparing patterns of intersectoral innovation diffusion in Taiwan and China: a network analysis. Technovation, 25(2), 155-169.

Chu, W.-w. (2009). Can Taiwan's second movers upgrade via branding? Research Policy, 38(6), 1054-1065.

Dahlander, L., \& Gann, D. M. (2010). How open is innovation? Research Policy, 39(6), 699-709.

Degenne, A., \& Forsé, M. (1999). Introducing social networks (A. Borges, Trans.). London: Sage.

Dess, G. G., \& Beard, D. W. (1984). Dimensions of organizational task environments. Administrative Science Quarterly, 29, 52-73.

Dickson, P., \& Weaver, K. M. (1997). Environmental determinants and individual level moderators of alliance use. Academy of Management Journal, 40, 404-425.

Dorogovtsev, S. N., \& Mendes, J. F. F. (2003). Evolution of networks: From biological nets to the internet and $W W$. New York: Oxford University Press.

Florida, R., \& Browdy, D. (1991). The invention that got away. Technology Review, 93, 42-55. SepOct.

Furman, J. L., \& Hayes, R. (2004). Catching up or standing still? National innovative productivity among 'follower' countries, 1978-1999. Research Policy, 33, 1329-1354.

Glasmeier, A. (1991). The high-tech potential: Economic development in rural America. New Brunswick, NJ: Center for Urban Policy Research.

Goyal, S., Leij, M. J. v. d., \& Moraga-Gonzales, J. L. (2006). Economics: an emerging small world. Journal of Political Economy, 114(2), 403-412.

Granovetter, M. (1982). The strength of weak ties: A network theory revisited. In P. V. Marsden \& N. Lin (Eds.), Social structure and network analysis (pp. 105-130). Beverly Hills: Sage.

Granovetter, M. (1992). Economic action and social structure: The problem of embeddedness (the sociology of economic life). Boulder: Westview Press.

Grossman, G. M., \& Helpman, E. (1991). Innovation and growth in the world economy. Cambridge: MIT Press.

Gulati, R. (1998). Alliances and networks. Strategic Management Journal, 19, 293-317.

Gulati, R., \& Gargiulo, M. (1999). Where do interorganizational networks come from? The American Journal of Sociology, 104(5), 1439-1493.

Gulati, R., Nohria, N., \& Zaheer, A. (2000). Strategic networks. Strategic Management Journal, 21, 203215. 
Hobday, M., Rush, H., \& Bessant, J. (2004). Approaching the innovation frontier in Korea: the transition phase to leadership. Research Policy, 33(10), 1433-1457.

Hu, M.-C., \& Mathews, J. A. (2005). National innovative capacity in East Asia. Research Policy, 34(9), $1322-1349$.

Hu, M.-C., \& Mathews, J. A. (2008). China’s national innovative capacity. Research Policy, 37(9), 14651479. doi:10.1016/j.respol.2008.07.003.

Hu, M.-C., \& Tseng, C.-Y. (2007). Technological interdependence and knowledge diffusion in the building of national innovative capacity: the role of Taiwan's chemical industry. Technological Forecasting and Social Change, 74(3), 298-312.

Huang, H.-C., Shih, H.-Y., \& Wu, Y.-C. (2011). Contagion effects of national innovative capacity: comparing structural equivalence and cohesion models. Technological Forecasting and Social Change, 78(2), 244-255. doi:10.1016/j.techfore.2010.07.017.

Irwin, M., \& Huges, H. (1992). Centrality and the structure of urban interaction: measures, concepts and applications. Social Forces, 71(1), 17-52.

Jackson, M. O., \& Rogers, B. W. (2006). Meeting strangers and friends of friends: How random are socially generated networks? American Economic Review.

Jang, S.-L., Lo, S., \& Chang, W. (2009). How do latecomers catch up with forerunners? Analysis of patents and patent citations in the field of flat panel display technologies. Scientometrics, 79(3), 563-591. doi:10.1007/s11192-007-2032-1.

Kawamoto, H. (2002). The history of liquid-crystal displays. Proceedings of the IEEE, 90(4), 460-500. doi:10.1109/JPROC.2002.1002521.

Kawamoto, H., Shieh, H.-P. D., \& Jang, J. (2007). Scanning the issue: special issue on LCD TVs. Journal of Display Technology, 3(4), 339-341.

Keller, W. (2004). International technology diffusion (pp. 752-782). XLII: Journal of Economic Literature.

Kogut, B. (2000). The network as knowledge: generative rules and the emergence of structure. Strategic Management Journal, 21, 405-425.

Koka, B. R., Madhavan, R., \& Prescott, J. E. (2006). The evolution ofinterfirm networks: environmental effects on patterns of network change. Academy of Management Review, 31(3), 721-737.

Könnölä, T., Smith, J., \& Eerola, A. (2009). Introduction: future-oriented technology analysis-impacts and implications for policy and decision making. Technological Forecasting and Social Change, 76(9), 1135-1137.

Krackhardt, D. (1992). The strength of strong ties: The importance of philos in organizations. In N. Nohria \& R. Eccles (Eds.), Networks and organizations: Structure form and action (pp. 216-239). Cambridge: Harvard University Press.

Madhavan, R., Koka, B. R., \& Prescott, J. E. (1998). Networks in transition: how industry events (re)shape interfirm relationships. Strategic Management Journal, 19, 439-459.

Mathews, J. A. (2005). Strategy and the crystal cycle. California Management Review, 47(2), 6-31.

Milliken, F. J. (1987). Three types of perceived uncertainty about the environment: state, effect, and response. Academy of Management Review, 12, 133-143.

Murtha, T. P., Lenway, S. A., \& Hart, J. A. (2001). Managing new industry creation: Global knowledge formation and entrepreneurship in high technology. Stanford: Stanford University Press.

Nohria, N. (1992). Introduction: Is the network perspective a useful way of studying organizations? (Networks and organizations: Structure, form and action). Cambridge: Harvard University Press.

Osterloh, M., \& Rota, S. (2007). Open source software development-just another case of collective invention? Research Policy, 36(2), 157-171.

Park, N., \& Mezias, J. M. (2005). Before and after the technology sector crash: stock market response to alliances of e-commerce firms. Strategic Management Journal, 26(11), 987-1007.

Parkhe, A., Wasserman, S., \& Ralston, D. A. (2006). Introduction to special topic forum new frontiers in network theory development. Academy of Management Review, 31(3), 560-568.

Powell, W., Koput, K., \& Smith-Doerr, L. (1996). Interorganizational collaboration and the locus of innovation: Networks of learning in biotechnology. Administrative Science Quarterly, 116-145.

Scott, J. P. (1991). Networks of corporate power: a comparative assessment. Annual Review of Sociology, 17, 181-203.

Spencer, J. (2003). Global gatekeeping, representation and network structure: a longitudinal analysis of regional and global knowledge-diffusion networks. Journal of International Business Studies, 34, 428-442.

Staw, B. M., \& Szwajkowski, E. (1975). The scarcity-munificence component of organizational environments and the commission of illegal acts. Administrative Science Quarterly, 20, 345-354.

Stolpe, M. (2002). Determinants of knowledge diffusion as evidenced in patent data: the case of liquid crystal display technology. Research Policy, 31(7), 1181-1198. 
Stowsky, J. (2004). Secrets to shield or share? New dilemmas for military R\&D policy in the digital age. Research Policy, 33(2), 257-269.

Tichy, N. (1980). A social network perspective for organization development (systems theory for organization development). Chichester: Wiley.

Tijssen, R. J. W. (2001). Global and domestic utilization of industrial relevant science: patent citation analysis of science-technology interactions and knowledge flows. Research Policy, 30(1), 35-54.

Turk, H. (1977). Organizations in modern life. San Francisco: Jossey-Bass.

Uzzi, B., \& Spiro, J. (2005). Collaboration and creativity: the small-world problem. The American Journal of Sociology, 111(2).

Verspagen, B., \& Duysters, G. M. (2004). The small worlds of strategic technology alliances. Technovation, 24(7).

von Hippel, E. (1988). The sources of innovations. New York: Oxford University Press.

Wilhite, A. (2001). Bilateral trade and 'small-world' networks. Computational Economics, 18, 49-64.

Zander, I. (1999). How do you mean 'global'? An empirical investigation of innovation networks in the multinational corporation. Research Policy, 28(2-3), 195-213. 